\title{
Enunciación
}

\section{Corporrelatos del yo docente: el cuerpo tras la práctica pedagógica}

\section{Body narratives of me as a teacher: The body after teaching practice}

\author{
Raimundo Villalba Labrador ${ }^{1}$
}

Para citar este artículo: Villalba, R. (2016). Corporrelatos del yo docente: el cuerpo tras la práctica pedagógica. Enunciación, 21(1), 61-78.

Recibido: 30-abril-2016 / Aprobado: 31-mayo-2016

\section{Resumen}

En este artículo expongo una serie de imágenes, relatos y disertaciones para revelar el cuerpo del docente tras la práctica pedagógica. El abordaje implica reconocer la experiencia corporal de quienes somos considerados sujetos de saber y la incidencia que tiene sobre nuestros cuerpos en el territorio escolar. Para este propósito, compartiré los resultados de una experiencia de investigación-creación sobre mi condición corporal como docente en una institución educativa distrital (IED), a partir del reconocimiento de marcas que la experiencia ha dejado en mi cuerpo y el corporrelato como ruta metodológica de indagación y creación a partir de la escritura desde el cuerpo.

Palabras clave: escuela, docente, experiencia docente, lenguaje corporal, relato.

\begin{abstract}
In this article I present a series of images, stories and dissertations to reveal the teacher's body experience in teaching practices. This approach involves recognizing bodily experience of those who are considered subjects of knowledge and the impact it has on their bodies. For this purpose, I share results of a creation-research strategy about my bodily condition as a teacher in a public education institution. Such condition is expressed on the marks that teaching experience has left on my body and "corporrelato", a concept I coined as a methodological inquiry and creation device to write about the body.
\end{abstract}

Keywords: school, teacher, teaching experience, body language, narrative.

1 Magíster en Estudios Artísticos de la Universidad Distrital Francisco José de Caldas. Docente de la Secretaría de Educación Distrital. Correo electrónico: raimundovillalba@gmail.com 


\section{Corporrelato 1: sin fecha ${ }^{2}$}

¿Quién pensará que mi labor exige algo más de carne, algo más de voz?

El tiempo pasa y envejecemos; menos sonidos, gestos y acción.

Las piernas duelen, las venas afloran, los dolores aumentan y con ellos el cansancio y las arrugas.

Antes, paseaba por el salón sin necesidad de utilizar el escritorio; ahora, busco pausas para sentarme o recostarme sobre él.

El tiempo pasa y el cuerpo se agota. Es la ley de la vida de quienes en su práctica repiten los mismos movimientos.

Enseñar es bello, pero en esta belleza se esconden las espinas de la realidad.

Sobre esto son los relatos, sobre las espinas que se incrustan en el cuerpo del docente;

las espinas que adolecen de la experiencia del habitar la escuela:

un acto de resistencia.

Expongo una serie de imágenes, relatos y disertaciones para revelar el cuerpo del docente tras la práctica pedagógica. Este abordaje implica reconocer la experiencia corporal de quienes somos considerados sujetos de saber y la incidencia que tiene sobre nuestros cuerpos en el territorio escolar. Para este propósito, compartiré los resultados de una experiencia de investigación-creación sobre mi condición corporal como docente en una institución educativa distrital (IED), a partir del reconocimiento de marcas que la experiencia ha dejado en mi cuerpo y el corporrelato como ruta metodológica de indagación y creación a partir de la escritura desde el cuerpo.

Se atiende así, al autoconocimiento y conocimiento local sobre las experiencias vividas como docente en zona de vulnerabilidad que, comúnmente, no circulan en los relatos dominantes del quehacer docente. Además de reconocer que la

2 En este documento, uso la fuente cursiva y la alineación centrada para identificar los textos que denomino corporrelatos. condición corporal del docente es un campo incipiente en los estudios sobre el cuerpo en el entorno escolar (Cabra y Escobar, 2014; Rodríguez 2013). Parafraseando a Woods (1998), p.15 es principalmente por medio de uno mismo como se llega a conocer el mundo y, a la inversa, los descubrimientos que hacemos revierten sobre nuestra persona. De esta manera, se espera hacer contribuciones en la comprensión de la vida en la escuela, como institución humana, que no solo afecta a los estudiantes sino también a los docentes desde un yo colectivo en el que muchos podrán ver reflejadas sus experiencias.

\section{SOBRE LA CONDICIÓN CORPORAL DEL DOCENTE}

Desde hace tres años, me pregunto por la experiencia del docente en la escuela tras sentir cómo esta ha afectado mi cuerpo. Recuerdo que el desgaste reiterativo de la voz, por la acción comunicativa y pedagógica, iba formando carnosidades en las cuerdas vocales como marcas dolorosas de una labor. Desde entonces, empecé ser consciente del hacer docente como experiencia corporal, en un entorno de interacciones sensibles que dejan marcas en el cuerpo y alteran el cuerpo que soy; para este caso, la vivencia de un cuerpo desgastado en su voz.

Por lo anterior, considero el hacer docente una experiencia corporal; como bien refiere Mari Luz Esteban (2004): "[...] en cualquier cultura el cuerpo está íntimamente ligado a lo social, ya que toda práctica social es, de una manera u otra, una experiencia corporal" (p. 67). Los docentes habitamos la escuela con un rol sociocultural y profesional definido, pero este habitar no solo nos expone a experiencias pedagógicas sino que también, nos expone a tensiones, contradicciones, conflictos y posibilidades que generan el encuentro y desencuentro con sujetos, formas de pensar y hacer, relaciones de poder, historias de vida, percepciones, luchas, imaginarios, emociones, sentimientos..., que se cruzan en las interacciones sensibles y cotidianas en la comunidad escolar. 
En este escenario de fuerzas y tensiones, los docentes estamos expuestos a diferentes intercambios sensibles que afectan el cuerpo físico/químico, psíquico/social y energético que somos (Rico, 1998). No tenemos cuerpo, somos cuerpo, y por tanto, somos cuerpos sensibles, vulnerables y expuestos a nuestras propias experiencias.

La experiencia suena a finitud. Es decir, a un tiempo y a un espacio particular, limitado, contingente, finito. Suena también a cuerpo, es decir, a sensibilidad, a tacto y a piel, a voz y a oído, a mirada, a sabor y a olor, a placer y a sufrimiento, a caricia y a herida, a mortalidad. Y suena, sobre todo, a vida, a una vida que no es otra cosa que su mismo vivir, a una vida que no tiene otra esencia que su propia existencia finita, corporal, de carne y hueso (Larrosa, 2006, p. 110).

La experiencia del cuerpo es apertura de la sensibilidad, un intercambio energético y sensible con el mundo viviente y cultural, en palabras de Mandoki (2006), "la realidad es corpo-realidad pues el cuerpo precede y constituye todo sentido y toda estesis" (p. 65). El lugar de la experiencia es el sujeto, y por tanto, esta lo afecta, toca su cuerpo, su ser, su vida y posibilita cambios en su subjetivación, en lo que yo soy, en lo que yo pienso, en lo que yo siento, en lo que yo sé, en lo que yo quiero, etc. (Larrosa, 2006, p. 90).

\section{Corporrelato 2: martes 6 de agosto de 2013}

Cuando le pregunto al cuerpo por la escuela, me encuentro con mis miedos. Empiezo a reconocer que los docentes somos cuerpos vulnerables en el entorno laboral. Esta "cajita mágica" de juegos, colores, risas y aprendizajes a veces asfixia, ahoga, duele, lastima o amenaza.

Cada vez que pregunto, me encuentro con otras experiencias. Puedo percibir los miedos, las dolencias, las crisis, las incapacidades y la ausencia. He vivido la dolencia de la voz, del movimiento, de la interacción, del estrés... He conocido docentes agredidos en su profesión, desgastados por la labor y aburridos entre la incapacidad de enseñar.

Hay situaciones de la escuela que me indigestan, y aunque amo ser docente no me puedo anestesiar. Hay experiencias en la escuela que no son de colores sino a dos tintas $y$, aunque duelan, es necesario narrar.

La escuela congrega algo más que un lugar, es disciplina, discursos, disposición de espacios y cuerpos, imágenes, gestos, metodologías, currículo, reglamentos, clases, jerarquías, vigilancia, rutinas, emociones, historias de vida..., y una serie de situaciones que definen la experiencia de quienes la habitan. Por consiguiente, expongo aquí, un segundo acercamiento al cuerpo como contenedor de experiencias: el cuerpo soporta la carga cultural, social, política y laboral del territorio escolar. Desde esta perspectiva, el cuerpo da cuenta del modo en que el sujeto es afectado por su misma experiencia. Según Carolyne Myss (2006),

Nuestro cuerpo contiene nuestra historia, todos los capítulos, párrafos, estrofas y versos, línea a línea, de todos los acontecimientos y relaciones de nuestra vida. A medida que avanza la vida, nuestra salud biológica se va convirtiendo en un relato biográfico vivo que expresa nuestras fuerzas, debilidades, esperanzas y temores (p. 34).

Considerar el cuerpo como contenedor de la memoria de las experiencias, es reconocer al sujeto de la experiencia, como sugiere Larrosa (2006), una superficie de sensibilidad en la que la experiencia deja una huella, una marca, un rastro, una herida. Marcas que quedan de un acontecimiento determinado o que se han registrado en el tiempo, como el caso de las lesiones de voz.

Dado lo anterior, propongo la categoría marca corporal para indicar el registro carnal, sensible o emocional de afectación de la experiencia en el docente. De manera más concreta, la marca es un indicio (sentimiento, emoción, dolor, rasgo en la piel, imágenes sensibles, sonidos, olores...) que tiene relación de causalidad con lo vivido en la escuela. Por tanto, preguntar por la causa de la marca es indagar por las experiencias vividas, que al interpretarlas, contextualizan y problematizan dicha condición. Para este propósito he de utilizar el corporrelato como recurso metodológico de indagación de la experiencia corporal. 


\section{EL CORPORRELATO: RELATO DESDE EL CUERPO}

En esta línea discursiva, presento el corporrelato como una ruta metodológica para vaciar el cuerpo y registrar la experiencia docente a través de la escritura. Su intención es reconocer las marcas en el cuerpo del docente para provocar la memoria y reconstruir la experiencia emocional y sensible a través del relato. Un dolor, un gesto, una emoción, una sensación, una imagen, un recuerdo..., de lo que aconteció son indicios para rememorar la experiencia en narrativa.

\section{Corporrelato 3: lunes 9 de septiembre de 2013}

Celebro el saludo que recibo diariamente de una estudiante de diez años. Por alguna razón, desde que me siento frágil, ella me recibe en las mañanas con un fuerte abrazo, acompañado de un emocionante:

$$
\text { - ¡Profe Ray! }
$$

Su sonrisa me hace cálida la fría mañana. El gesto es aliento, aire de vida que se registra en la piel y en los huesos. Siento el abrazo como una motivación más para estar.

En la noche, cierro los ojos pensando que al otro día, alguien me espera en la escuela.

El corporrelato lo equiparo a una práctica analítica y creativa, en la categoría de Laurel Richarson (como se citó en Feliu y Lajeunesse, 2007), que mezcla el lenguaje del arte con el de las ciencias sociales para producir conocimiento social a través de una práctica creativa. Así, el corporrelato es otra posibilidad más en la producción del conocimiento, al dar paso a las prácticas locales y subjetivas para comprender las formas posibles de la existencia humana, ya que el conocimiento se encuentra entrelazado con las vidas concretas y las experiencias personales, a tal punto que, el conocimiento en sí, no deja de ser una narración más que participa en el mundo de las narraciones sobre la vida (p. 267).
Por otro lado, la escuela, como institución humana, reproduce estereotipos que se han arraigado en su ejercicio de socialización (Foucault, 2009; Mandoky, 2006; Pedraza, 2011). Por ejemplo, los discursos dominantes sobre el perfil del estudiante, del docente y de la escuela promulgan un prototipo que excluye otras existencias. En consecuencia, los docentes vamos encarnando estos discursos y prácticas para reproducir la manera como "se debe habitar el entorno escolar" que se ponen en tensión con las violencias simbólicas que resisten los discursos dominantes. Por tanto, el corporrelato, como portador de nuestra experiencia, da cuenta de estas tensiones y experiencias; de lo que vivimos, sufrimos, gozamos y de las luchas que hemos tenido ante las disposiciones socioculturales en que vivimos. Tal como lo sugiere Jesús Martín Barbero (2014),

"Contar" es tanto narrar historias como ser tenidos en cuenta por los otros. Lo que significa que para ser reconocidos necesitamos contar nuestro relato, pues no existe identidad sin narración, ya que esta no es solo expresiva sino constitutiva de lo que somos (p. 7).

Los corporrelatos contienen la experiencia y, al mismo tiempo, las reflexiones y emociones del docente investigador que al interpretarse a través de una herramienta analítica contribuyen a develar conocimiento de la experiencia escolar.

Para sintetizar este primer momento discursivo, concluyo que somos cuerpos construidos entre múltiples experiencias que componen un material diverso de huellas y memorias que dan cuenta de lugares y tiempos que hemos habitado y que se han incorporado en nosotros como signo cultural de nuestra existencia. Desde el cuerpo el relato acontece como testimonio de experiencias de vida local del sujeto que posibilita diversas miradas no hegemónicas de la realidad y la comprensión de la condición humana en instituciones como la escuela. Desde esta perspectiva, me pregunto por el docente desde la carnalidad de su experiencia, quien deja de ser un ente abstracto del discurso pedagógico para reconocerse como sujeto encarnado con 
un rol sociocultural en una institución humana y moderna; una manera de comprender su existencia desde los lugares del sentir (Mandoki, 2006).

\section{SOBRE LO ENCONTRADO, DEVELADO Y CREADO DESDE EL CUERPO}

\section{Corporrelato 4: martes 6 de agosto de 2013}

Al contemplarme en el espejo, me pregunto:

¿Qué reside de la escuela en este cuerpo?

¿Qué contiene la piel, órganos, huesos, músculos, corazón, mente y alma?

¿Qué ha vivido?

El cuerpo del docente revela la sombra de carne de su estereotipo.

En su cuerpo están inscritas las experiencias que acontecen en la escuela

A continuación ${ }^{3}$, expongo brevemente los resultados narrativos y analíticos de una experiencia de investigación-creación para revelar y comprender la condición corporal de un docente de primaria en una institución educativa distrital (IED) a partir de marcas en el cuerpo. Estas últimas, correlacionadas por criterios de afectación corporal y características de la experiencia, develaron a través de los corporrelatos seis condiciones corporales de su experiencia docente en la escuela:

1. Cuerpo desgastado.

2. Cuerpo vulnerable.

3. Cuerpo autoritario.

4. Cuerpo silenciado.

5. Cuerpo creativo.

6. Cuerpo cuidador.

Las veintinueve experiencias autonarrativas desde el cuerpo (corporrelatos) dan cuenta de la condición corporal como experiencia circunstancial, situada, contextuada y encarnada en la escuela. Por

3 El yo discursivo que inició este artículo intenta hacer un distanciamiento para la voz analítica y se retoma en los fragmentos de los corporrelatos. tanto, presento a modo de ilustración las marcas en el cuerpo de cada condición corporal develada del docente, acompañado de un resumen analítico y fragmentos de corporrelatos.

\section{Cuerpo desgastado}

Los docentes estamos expuestos a factores de riesgos que devienen del hacer profesional. En la interacción permanente con el medio se manifiesta el desgaste corporal como el conjunto de marcas a causa de sus labores cotidianas. El cuerpo se vive como herramienta de la acción pedagógica, como plantea Marcel Mauss (como se citó en Esteban, 2014), el cuerpo es el primer instrumento del hombre y más normal, por lo que, cada sociedad impone al individuo el uso rigurosamente determinado de su cuerpo. Este es el principal instrumento del docente: su voz, sus movimientos, los gestos, la acción..., forman parte de las técnicas corporales que ha incorporado de la tradición escolar para ejercer su labor en la escuela.

De esta experiencia laboral, la disfonía es la primera marca corporal a señalar en la condición de cuerpo desgastado, al padecer afectaciones de la voz por esfuerzo y sobreuso en actividades laborales cotidianas (Alves y Nuño, 1996; Cantor, 2009; Pérez y Preciado López, 2003; Preciado, Pérez, Calzada y Preciado, 2015). La relación de causalidad entre el hacer y el desgaste corporal, deviene, en principio, de la manera como el docente concibe su lugar en el acto comunicativo pedagógico: la preferencia y tendencia a ser el emisor.

Hablé durante casi todo el tiempo de la clase. Mi posición como maestro me alienta a aprovechar cada situación para hacer presente el discurso. Recuerdo que utilicé diferentes tonos de voz, en especial los altos para llamar la atención de los distraídos y hacer énfasis en ciertos puntos del discurso. Aunque tomo agua después de cada intervención, como lo recomendó el terapeuta, a veces retomo la palabra entre un "gallo" y otro, y después de tanto hablar siento el cansancio, el dolor en la garganta y la sensación de ronquera. 


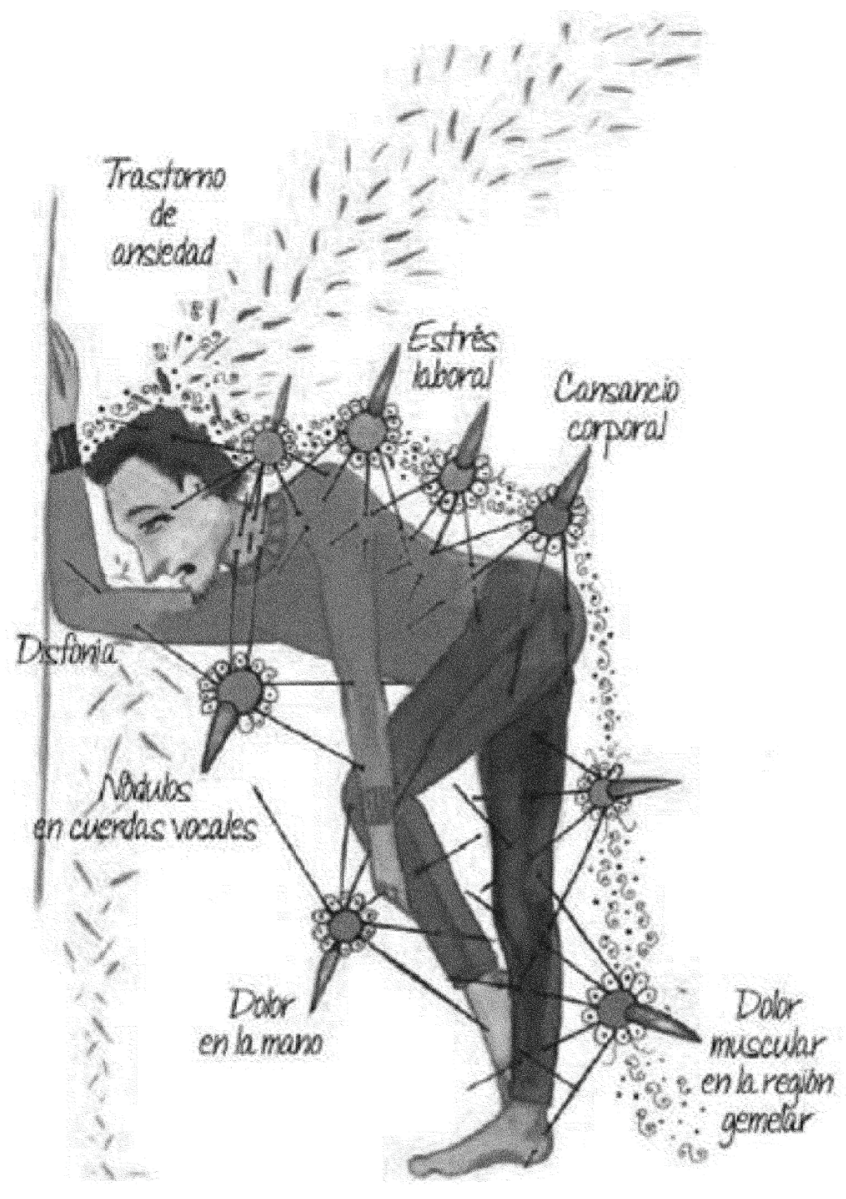

Figura 1. Marcas del cuerpo desgastado

Fuente: ilustración elaborada por Diana Otálora.

La conducta cotidiana del docente en la escuela es estar en comunicación oral-verbal constante como acción principal de su hacer pedagógico. A modo sensible, su voz circula en diferentes registros (ritmo, tono, intensidad y volumen), de acuerdo con el contexto, la ocasión y la intención del acto comunicativo. La voz es el recurso corporal utilizado para cumplir el propósito pedagógico y el dispositivo de control del ambiente escolar.

Por lo tanto, gritar, forzar la voz, hablar constantemente y por tiempo prolongado es un modo de relación sensible del docente en el entorno escolar. En consecuencia, el uso frecuente, cotidiano y excesivo de esta actividad corporal afecta su voz al favorecer el desarrollo de la disfonía y nódulos de cuerdas vocales como las marcas corporales de un cuerpo desgastado en su aparato fonador.
Otras de las marcas en el cuerpo desgastado están asociadas a factores ergonómicos. La postura constante, los movimientos repetitivos y la intensidad que puede llegar a alcanzar una actividad o una acción en el entorno escolar traen como consecuencias cansancio corporal y dolores musculares. La imagen del docente en acción, soportado sobre sus piernas (bipedestación), es la vivencia de la postura corporal constante. Esta postura vertical asienta el énfasis osteomuscular en las piernas, en consecuencia, después de la jornada laboral, el docente manifiesta dolor muscular en sus miembros inferiores y en la zona de los gemelos, estableciendo una relación de causalidad entre la rutina corporal y el dolor. Así mismo, el docente de los corporrelatos ha incorporado el ritmo rápido, emocional y en constante cambio de actividad 
de los estudiantes de primaria como respuesta a la demanda laboral. Entonces, mover, cortar, pegar, hablar, regañar, explicar, corregir, revisar, notificar, saludar, escribir y cada 30 minutos cambiar de actividad forman parte de su rutina $y$, al finalizar la jornada laboral, termina cansado tras el degaste energético del continuo movimiento muscular.

Lo que ha permanecido igual es estar de pie. La presencia en el aula la vivo sobre mis dos piernas, me soporto en ellas como imagen del cuerpo docente en acción. En el aula camino entre filas y espacios mientras observo y hablo a los estudiantes. En el patio estimulo el movimiento, la exploración del cuerpo físico; acompaño a quienes zanquean o zanqueo con ellos; juego o interpreto el clarinete. Creo que integré el ritmo de trabajo de los niños de primaria a mi estilo profesional.

Sentir dolor en la mano derecha es otra marca de desgaste relacionada con movimientos repetitivos. El cuerpo sometido (que describe los corporrelatos) revela la condición de un cuerpo disciplinado, obediente y programado para una serie de actividades que se repiten en la cotidianidad. En el caso del docente de primaria el énfasis corporal está puesto en la motricidad fina para elaborar las tareas básicas de su hacer: escribir en el tablero y en los cuadernos, dibujar, colorear, pintar, recortar, pegar, borrar, digitar, entregar, calcar, calificar, recoger... son modos de relación sensible que por exceso y rutina desencadenan molestias musculares evidenciadas a través del dolor.

El estrés laboral es otra marca del cuerpo desgastado y se manifiesta al percibir que las actividades de la escuela se salen de su control y no puede responder en la manera deseada o esperada. Entonces, en situaciones de indisciplina o no control de las acciones en el aula que dispersan el objetivo pedagógico; en el desajuste de su tiempo personal con el tiempo institucional que regula las actividades escolares (el calendario académico, el currículo, el horario de clases, la hora de clase...); en el exceso de trabajo y otras situaciones de conflicto... se manifiesta el estrés como un desequilibrio percibido entre las demandas profesionales y la capacidad del docente para Ilevarlas a cabo (Ayuso, 2006, p. 6).

Tengo mucho trabajo por hacer en la escuela: las clases, la disciplina, la comparsa, las evaluaciones, atender a padres, resolver conflictos... El tiempo no alcanza y esto me inquieta. Y la inquietud se cruza con las dinámicas cotidianas: los regaños, las tensiones, el ir de prisa, el cambiar de actividad, las preocupaciones, la responsabilidad...

Cuando el estrés no es controlado puede generar estado continuo de ansiedad, tensión, ira, descontrol y múltiples síntomas psicosomáticos como dolores de cabeza, insomnio, alopecia, gastritis..., y trae consigo otra marca corporal: el trastorno de ansiedad (Arón y Milicic, 2000; Cardona, 2011; De la Torre, 2007). El docente concibe la escuela como ambiente laboral vulnerable al vivenciar y rememorar condiciones y situaciones que han afectado su salud y desempeño. La ansiedad se manifiesta como un estado de desequilibrio en la percepción de la escuela cuya enfática está puesta en las experiencias negativas que recuerda y vive el docente. En consecuencia, siente los síntomas como respuesta corporal a su percepción de afectación: alteración del sistema nervioso, náusea, perturbación del sueño, miedos, sensación de vulnerabilidad, intranquilidad... El estado de estrés y la ansiedad son marcas del cuerpo desgastado asociadas a factores psicolaborales.

Cometí un error: somaticé la vulnerabilidad de sentirme docente en la escuela. Como una esponja absorbí las emociones, imágenes, sentimientos y recuerdos de los acontecimientos negativos, y esto me afecta. Hay situaciones que provocan tensiones grises que se desplazan del cerebro al estómago. Entonces, el corazón palpita más rápido y la sangre recorre las arterias como tren sin frenos. De pronto, surge el deseo no deseado de vomitar, de escupir algo atascado en las entrañas y salir corriendo. Corro, corro, corro, y por más que lo hago no puedo escapar. Aparece la intranquilidad. Anoche no pude dormir... me atrapan los miedos. 
En estas circunstancias, es paradójico evidenciar en el docente que la condición de cuerpo desgastado es tolerada a causa del logro pedagógico y profesional. El placer del trabajo escolar aguanta el desgaste corporal y lo justifica hasta encontrarse con el límite: el dolor y la incapacidad. Se percibe a sí, la imagen de un docente apóstol que se sacrifica así mismo por su obra, concibiendo la docencia como una labor altruista, vocacional y de sacrificio del cuerpo por la acción pedagógica.

Para concluir, el docente de los corporrelatos está expuesto a factores de riesgos que devienen de su hacer laboral y afectan su cuerpo como indicios de patologías laborales. Los trastornos de
vOz, dolores musculares, el estrés y la ansiedad son marcas corporales del desgaste y afectación que ha dejado la experiencia del habitar la escuela en el docente como evidencia de los modos de relación sensible con el entorno escolar.

\section{Cuerpo vulnerable}

Nos convoca otra vez el miedo.

El sentimiento incorporado durante los últimos años en la institución tras vivenciar situaciones de amenazas a docentes para excluirlos del territorio escolar. En estos momentos, deseamos el traslado masivo; sentimos miedo de permanecer, de que nos quiten el habla, los gestos, el movimiento... la vida.

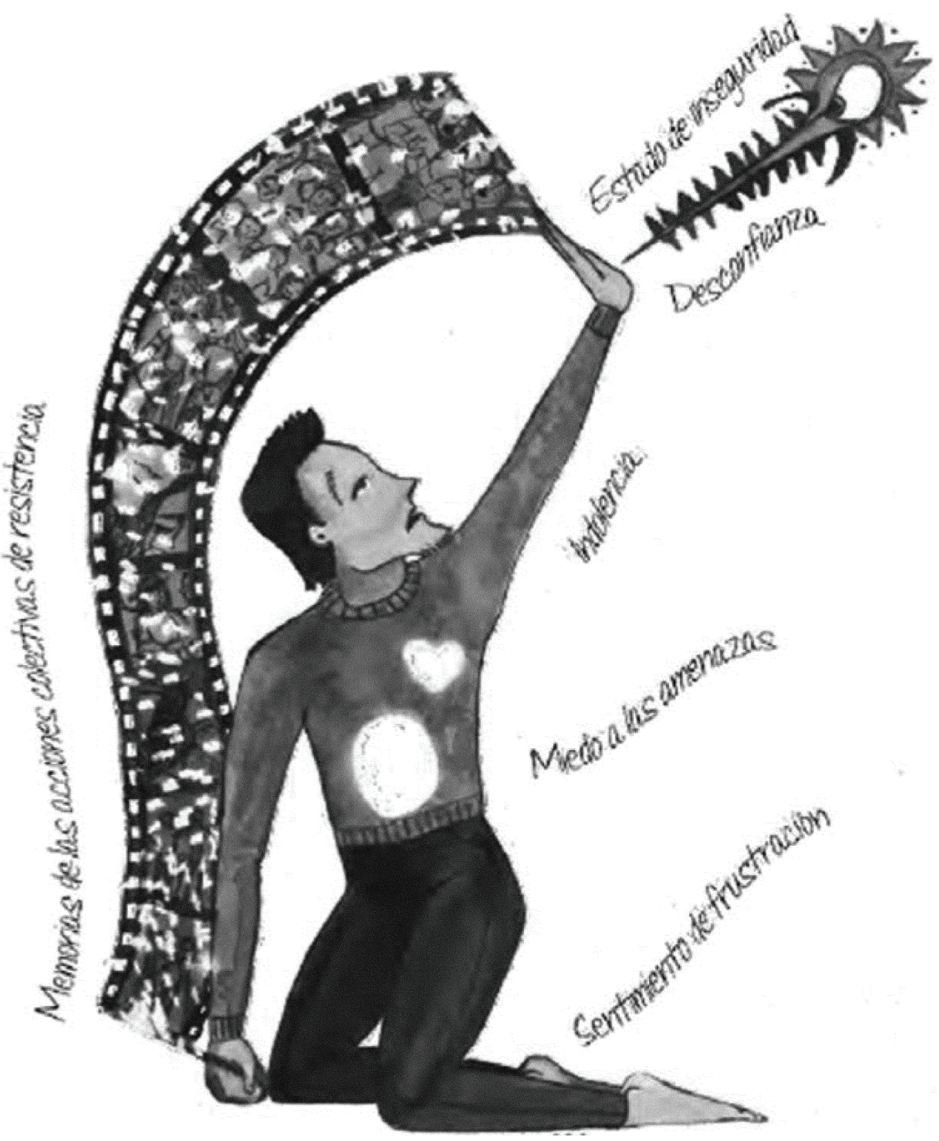

Figura 2. Marcas del cuerpo vulnerable

Fuente: ilustración elaborada por Diana Otálora. 
Hay experiencias otras en la labor docente que no son incluidas en los relatos dominantes de su hacer. El hurto, el robo y las amenazas a docentes son un ejemplo de estas experiencias, narradas en los corporrelatos del docente, y revelan la condición de vulnerabilidad en el entorno escolar. La marca corporal reiterativa de la experiencia de ser cuerpo vulnerable es el miedo, y junto a este, el sentimiento de frustración al no percibir condiciones dignas para ejercer su labor.

El docente tiene miedo de habitar la escuela y este estado emocional se contrasta con la naturaleza y los valores morales que reproduce el entorno escolar. La relación afectiva del docente con la escuela se fractura y acontece el deseo de traslado de institución y localidad como necesidad de bienestar. En estas condiciones el interés pedagógico deja de ser prioritario y la vivencia en la escuela está centrada en el estado de fragilidad y de protección.

Amenazaron a docentes y estudiantes de la jornada de la tarde. En la sala de profesores hay un sentimiento de frustración y tristeza ante la incapacidad de resolver el conflicto en la escuela. El ideal pedagógico de transformación social ha fallado, hemos hecho todo lo que estaba a nuestro alcance para encontrarnos con el límite. No aguantamos más. Nos dejaron sin voz y sin acción

Entonces, ante cada acto de amenaza acontece la resiliencia como acción comunitaria, creativa y restauradora para recuperar el sentido y la confianza en la escuela. Pero las amenazas al repetirse por meses y años, van formando parte de la vivencia cotidiana de la escuela y los docentes se acostumbran a estas. En consecuencia, el mecanismo de defensa para habitar la escuela deja de ser colectivo y se asume como acción personal desde la indolencia.

Esta es la escuela que no me enseñaron en la Normal ni en la universidad:

La no contada, la ignorada, la silenciada, la del susurro.

\section{Cuerpo autoritario}

Algo que aprendí en la escuela fue a ejercer la disciplina a través de la mirada. Lo aprendí una vez, al observar a una maestra que se paraba en la puerta del salón, cruzaba los brazos a la altura del pecho y con el rostro serio miraba al grupo. Luego enfocaba sus ojos en cada uno de los estudiantes indisciplinados

que no se habían percatado de su presencia.

El cuerpo autoritario lo ha encarnado el docente tras reconocer y reproducir prácticas estereotipadas de autoridad moral, social y corporal en la escuela, como modos de relación sensible en su espacio escolar. La enfática del registro somático, acústico y escópico están centradas en el poder y el control: organiza los cuerpos de los estudiantes en filas, el cuerpo del docente permanece de pie, se le admite el tono de voz alto, arruga el rostro, se ubica en puntos estratégicos para vigilar y reprender los cuerpos de los estudiantes. El cuerpo autoritario reproduce, como denomina Tarruella y Rodríguez (2008, p. 2), rituales corporales de los docentes para construir una presencia de cuerpo a partir de la repetición de sus usos ordenados.

La disciplina, como dispositivo de control para los estudiantes, deviene de una concepción anatomopolítica sobre los cuerpos (Foucault, 2009). "El ejercicio de la disciplina supone un dispositivo que coacciona por el juego de la mirada, un aparato en el que las técnicas, que permiten ver, inducen efectos de poder a aquellos a quienes va dirigido" ( $p$. 158).

Esa vez, me impresionó la fuerza de la mirada para generar respuestas en los estudiantes; de un momento a otro, ellos se iban organizando en el salón hasta quedar en sus puestos por filas.

El docente ha encarnado un cuerpo sujeto del poder, que es objeto de un poder institucional. Así, además de educar y dar forma al 
cuerpo del estudiante, se ha educado y dado forma a sí mismo, cuyas fuerzas y habilidades corporales dan respuestas a una tradición instaurada en el contexto escolar.

Cuando jugaba a ser docente, imitaba la voz, la postura, los gestos, la mirada y el estar de pie de mis maestras de primaria.

Incorporar la práctica corporal de vigilancia y control a través de la mirada en su experiencia laboral, evidencia que el docente valora este gesto como estrategia corporal efectiva para mantener y regular los cuerpos en la escuela. Pero, cuando la técnica disciplinar de la mirada no es suficiente para docilitar los cuerpos indisciplinados, aparece el cuerpo alterado: manifestaciones sensibles de exaltación emocional a través del grito, la coloración de su piel, las arrugas en su cara y el enojo de su mirada; una extravagancia de su corporalidad para regular y reincorporar los cuerpos a la estructura escolar concebida por tradición. Estos gestos corporales de control son las marcas del cuerpo autoritario.

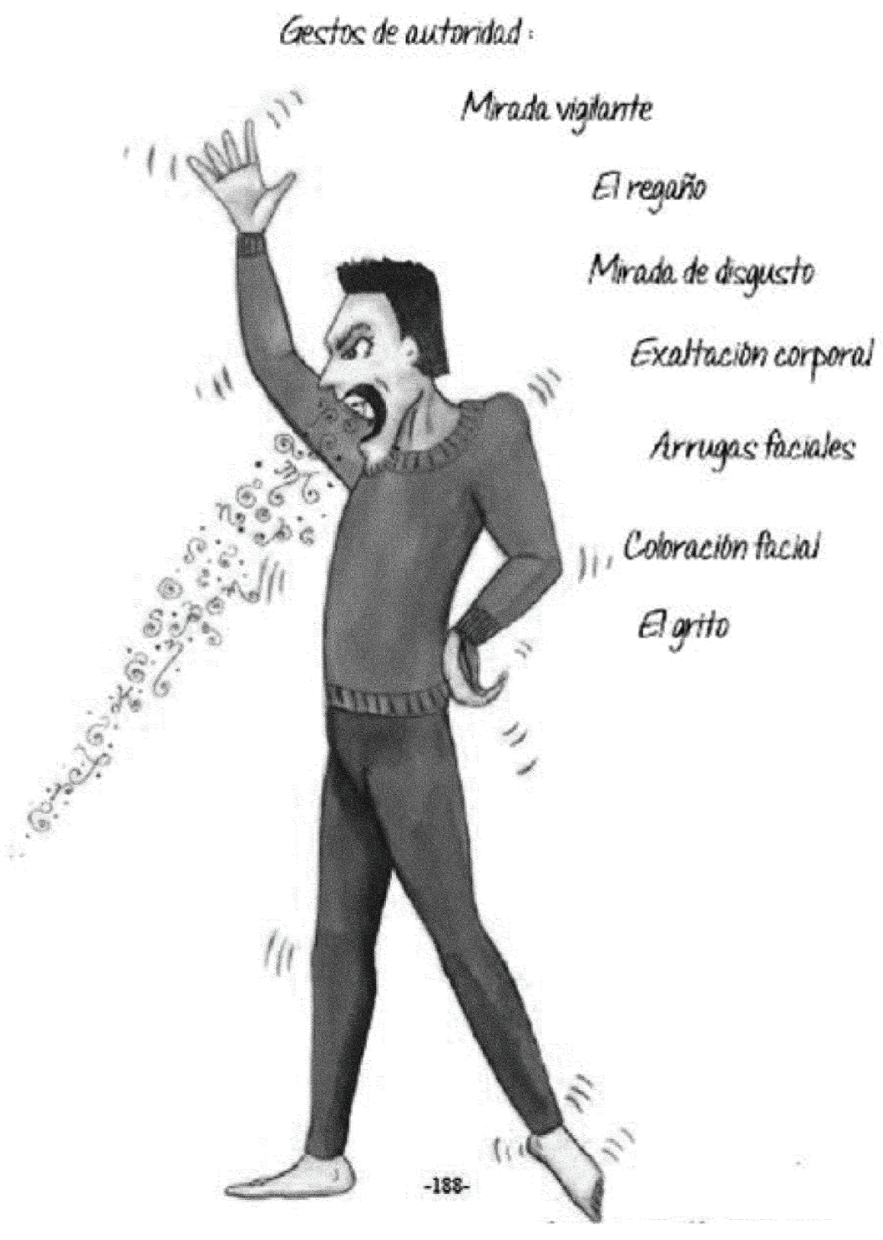

Figura 3. Marcas del cuerpo autoritario

Fuente: ilustración elaborada por Diana Otálora. 


\section{Cuerpo silenciado}

12:30 p.m. Finaliza la jornada escolar. Antes de salir, como de costumbre, me dirigí al cuarto de los vigilantes para firmar la salida. Los estudiantes de bachillerato estaban en el patio esperando a que empezara la siguiente jornada. Mientras firmaba, escuché a un estudiante decir: -iProfe gay!

Con el toque de burla que acompaña la etiqueta.

Los corporrelatos revelan que el docente ha encarnado el régimen heterosexual que reproduce la escuela al vivenciar desde el silencio, el miedo, la tristeza y la reproducción de comportamientos masculinos para invisibilizar gestos repartidos sensiblemente al rol femenino. La acción restrictiva del cuerpo homosexual en el entorno escolar es la condición corporal del cuerpo silenciado.

Hubiera deseado devolverme y hacer un acto pedagógico, pero terminé haciendo lo que hacía desde niño: silenciar, simulando no haber escuchado, mientras me engullía un rojo intenso de indignación $y$, al mismo tiempo, la tristeza de sentir pena ante la impotencia para dibujar con técnica masculina formas gruesas, más azules, más fuertes, más ortodoxas, más repetitivas, más estáticas, más oscuras...con el cuerpo.

Hay una estesis corporal que se adhiere en la construcción social del género en los cuerpos. Una estética en el registro somático, léxico, acústico y escópico, con una enfática de género femenino para las mujeres y una enfática de género masculino para el caso de los hombres (Mandoki, 2006). Pero cuando las enfáticas corporales no están en correspondencia con las enfáticas hegemónicas acontece el señalamiento y la exclusión. Y entonces, la voz, el léxico, el movimiento, el tono corporal, los gestos y el vestir son rasgos de observación y valoración, aceptación o exclusión.

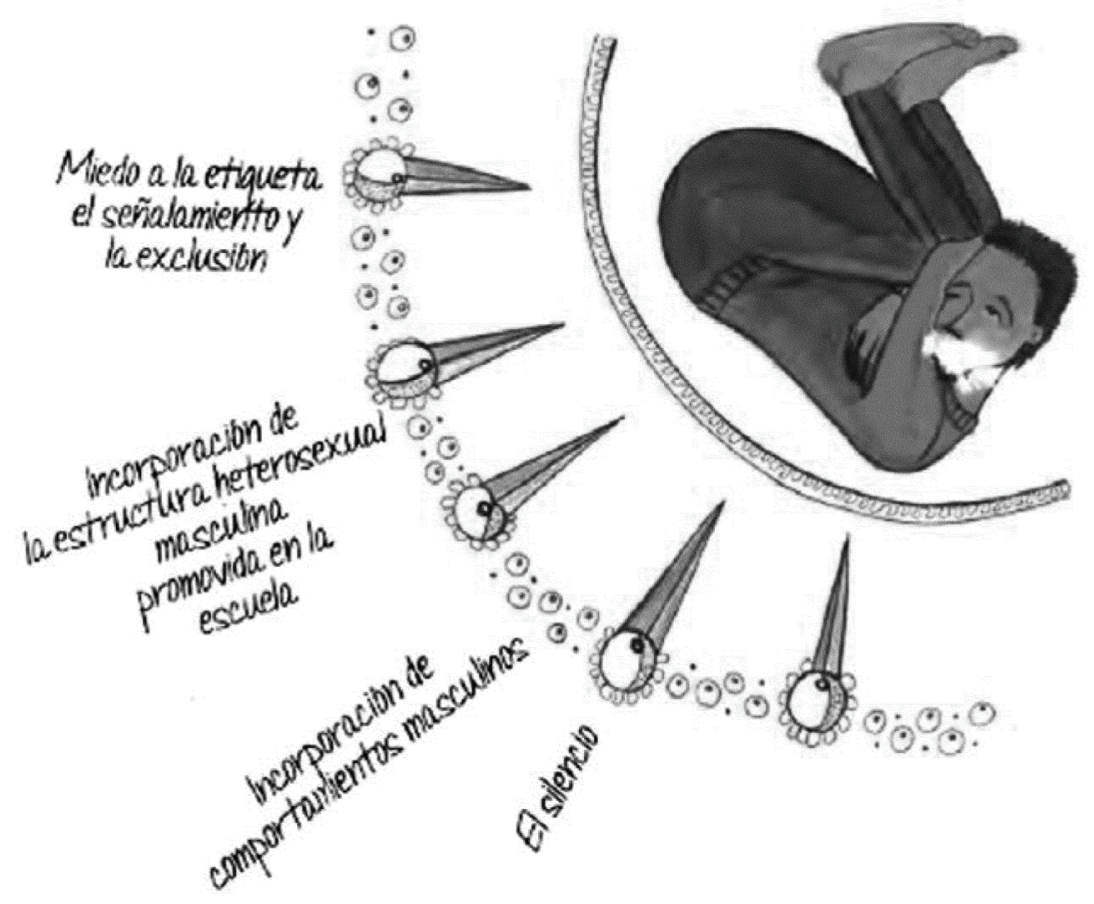

Figura 4. Marcas del cuerpo silenciado

Fuente: ilustración elaborada por Diana Otálora. 
En el campo del surgimiento de la sexualidad en el Occidente moderno esta operación ideológica se manifiesta en la creación de la heterosexualidad obligatoria. La ley actúa en su función represiva que efectivamente produce la heterosexualidad, pero por exclusión -expulsión/repulsa- crea el homosexual como otro subalterno (Figari, 2009, p. 132).

Los docentes no escaparon a este proyecto moderno porque en sus manos se les asignó el poder de reproducción corporal de estos perfiles en masas a través de la escuela. Así, el docente es el cuerpo ejemplo de este ideal moderno, cuyo perfil, preferiblemente, se condiciona a una vida ejemplar, casado, heterosexual, disciplinado, trabajador, sabio... "El cuerpo también se enseña y se aprende, sin la mediación del orden discursivo, es decir de manera directa, a través de prácticas sociales cotidianas y concretas" (Tarruella y Rodríguez, 2008, p. 2).

De modo que se fortalecen y circulan las representaciones y los discursos sobre la heterosexualidad como formas de relación cultural y social válidos que incorporan los miembros en la escuela, materializando así el proyecto moderno y cristiano de la familia. De modo que la tensión entre lo público/normal (heterosexualidad) y lo privado/anormal (homosexualidad), lo resuelve el docente con el silencio. Por tanto, el silencio es el modo de relación del docente desde un sistema de estructura social incorporado que actúa como dispositivo de autocensura de su condición homosexual.

El proyecto moderno de la heterosexualidad se legisló para los docentes en Colombia con el Decreto-Ley 2277 de 1979, Estatuto Docente, artículo 46, el cual valoró el homosexualismo como mala conducta, discriminó a los docentes por su orientación sexual y definió sanciones como la destitución definitiva del cargo. Esta ley se mantuvo regulando el cuerpo docente del país por diecinueve años hasta que la Sentencia C-481/98 debatió e impugnó este artículo al determinar que la "homosexualidad no es falta disciplinaria en el ejercicio docente", indicando los derechos que promulga la Constitución de 1991 (Amézquita, 2012, p. 16).
Sin embargo, aunque la legislación respalde el derecho a la diversidad, el docente se siente vulnerado con la etiqueta "gay". De seguro, los prejuicios aún se conservan. La Encuesta Docente Bogotá 2009 (Londoño et al., 2011) evidenció que los docentes del Distrito son poco tolerantes al homosexualismo. Al preguntarles si "a los homosexuales se les debe permitir ser profesores de colegio", la mayoría (57,2 \%) estuvo en desacuerdo, lo que evidencia la "persistencia de arraigados prejuicios contra los homosexuales, no obstante todo cuanto se ha hecho en Bogotá para fomentar la tolerancia y la valoración de las diferentes opciones sexuales, y para proteger la población LGBT" (p. 167).

Para concluir, el cuerpo silenciado del docente es el cuerpo que se relaciona desde el silencio de su género tras la concepción de heterosexualidad masculina encarnada y el miedo a la etiqueta, el señalamiento y la exclusión como marcas en su cuerpo. De ahí que el docente busca incorporar representaciones sensibles heterosexuales masculinas en la cotidianidad que se ponen en tensión con su corporeidad. De otra manera, encarna el dispositivo de un cuerpo heterosexual masculino, pero vivencia un cuerpo con otras tonalidades que se hace presente en su condición de docente.

Por más que trato de actuar lo más azul posible, algo fluye, algo rosa se colorea en mí.

\section{Cuerpo creativo}

La primera comparsa creada en la escuela tuvo sus orígenes en una tarde de música y color sobre una importante avenida del centro de la ciudad. La maravillosa experiencia de ser un feliz comparsero azul con la cara naranja fue la motivación necesaria para incluir la escuela en las festividades de la ciudad y compartir esta experiencia con los estudiantes. Asumí, entonces, el reto de hacer realidad este sueño y-con la ayuda de algunos docentes, padres de familia, directivos y estudiantes-creamos el primer cuerpo festivo que desfiló por las calles de la ciudad. Así, transité de la clase de danzas hacia la comparsa, ampliando la experiencia artística a través de la música, el teatro, la plástica y el lenguaje festivo. 


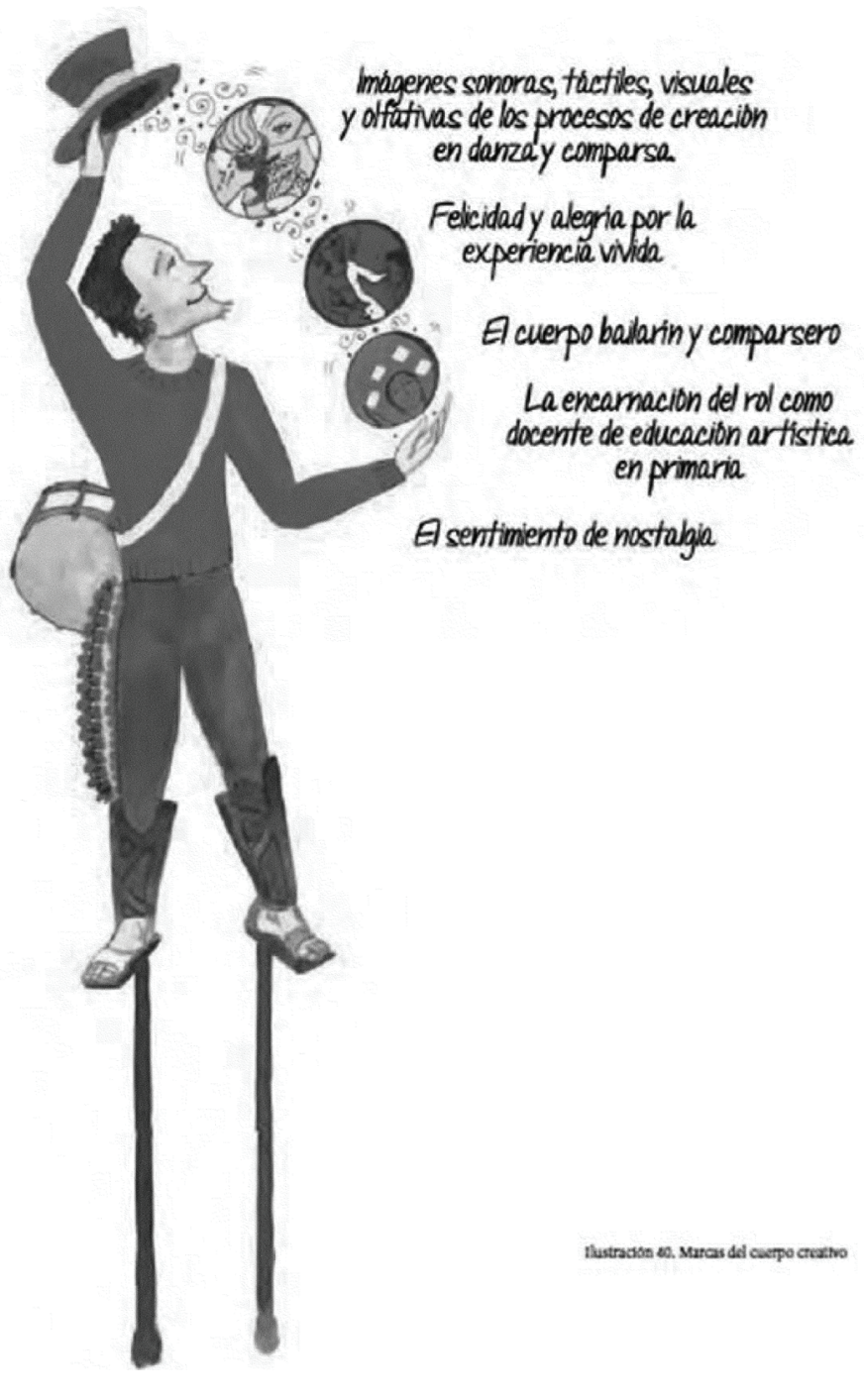

Figura 5. Marcas del cuerpo creativo

Fuente: ilustración elaborada por Diana Otálora.

Los corporrelatos revelan el cuerpo creativo desde la experiencia vivida como docente de educación artística en la escuela tras afectar las prácticas corporales cotidianas a través de la danza y la comparsa. Crear, desde las prácticas artísticas, fue el sentido que encontró el docente para habitar la escuela; razón por la cual fomenta experiencias creativas con los estudiantes para consolidar un cuerpo colectivo que dialoga su realidad sociocultural con la experiencia creativa y poética de la danza, el teatro, la música y la comparsa. De esta manera, el cuerpo creativo irrumpe con las condiciones tradicionales y regulares de la escuela para escabullirse entre la fiesta y la comparsa.

El movimiento se piensa entonces como una posibilidad vital, creativa, expresiva, que tiene el potencial de transformar y mejorar la vida de los seres humanos $[\ldots .$.$] . Esta postura deriva del hecho de que$ la escuela se dedica a aquietar los cuerpos, en lugar de pensar en las potencialidades de su movimiento (Cabra y Escobar, 2014, p. 154). 
A través de los proyectos artísticos y comunitarios, el docente vivencia la escuela como territorio de resistencia y re-existencia que se contrasta con las experiencias de vulnerabilidad o desgaste corporal. De modo que encuentra un punto de fuga hacia otra posibilidad de ser, estar y hacer; $y$ de permitir estas posibilidades a los estudiantes. La re-existencia estaría en transmutar la vivencia cotidiana del cuerpo dócil al cuerpo creativo a través de la transmutación de los valores, permitiendo construir otras existencias, modos de vida y subjetivaciones en la escuela (Pabón, 2002, p. 69).

Configuro un cuerpo nuevo, otra presencia, un cuerpo creador en diálogo con el movimiento, la música, el juego coreográfico, la sonrisa y la creación. Empecé a compartir mi experiencia en danza y teatro callejero con los niños en la escuela. Y en la experiencia se añadió el vestuario de colores, el maquillaje, los tonos de voz, los instrumentos musicales, la grabadora, el salón de comparsa, la acción, el juego, la creación y la función escénica. Ser docente de artes fue un deseo que se hizo carne en la escuela.

El cuerpo creativo, responsable del quiebre del cuerpo vulnerable, del cuerpo autoritario y del cuerpo tradicional docente, sana, equilibra y fortalece su relación con la escuela a través de las prácticas artísticas como modos de relación con el entorno escolar. En consecuencia, las marcas que habitan en su cuerpo son imágenes sensibles de estas experiencias; la memoria que justifica su presencia en la escuela.

La comparsa era el proyecto creativo más importante del docente de artes. El tiempo, los talleres, los aprendizajes, los descubrimientos, las interacciones y la energía se condensaban en una presencia efímera que se desplazaba por la Carrera Séptima. La memoria evoca la fuerza del gesto creativo de los estudiantes y el goce de lo que estaban viviendo. Hicieron suyos el vestuario, el maquillaje, el personaje, los movimientos, la música, la alegría y la narrativa. Era una fiesta que nos congregaba como duendes de colores entre las anchas calles y las extravagantes estructuras de cemento y vidrio que se elevaban hacia los cielos. De esta manera, muchos niños conocieron la ciudad; así lo contaban: se habían conectado con la otra ciudad que no conocían, la que solo veían en televisión y que era muy distinta a su localidad.

\section{Cuerpo cuidador}

Otro jardín es la escuela. Habitarla como docente es el deber para el cual me he preparado desde niño. Cuidar, velar, sanar, regar, abonar, construir... son las acciones que guían mi hacer. Debo abonar la escuela diariamente con palabras sabias, sonrisas, abrazos, proyectos, regaños, música, danza, color, imágenes, comparsas... Esa es la "estética" de mi ser docente, de mi clase y de mis estudiantes.

El cuidado del estudiante y la responsabilidad de la vida es la dinámica de concepción que ha incorporado el docente tras vivenciar experiencias de riesgos en la escuela. El cuidar, como plantea Boff (2002), "representa una actitud de ocupación, de preocupación, de responsabilización y de compromiso afectivo con el otro [...] un 'modo-de-ser'" (p. 29), que direcciona las acciones del docente en la escuela. En consecuencia, su hacer está enfocado a prevenir, advertir e indicar situaciones de riesgos para promover experiencias que contribuyen al bienestar del estudiante.

La escuela evita el dolor y el error, en cambio, promociona la perfección en las actuaciones humanas como consecución del bienestar y la felicidad. Sin embargo, cuando acontece un accidente se activa el estrés y el sentimiento de compasión en el docente como respuesta efectiva para atender la situación. Luego, deviene el estado de autoculpa, como marcar emocional, al valorar el accidente como un evento no deseado y no previsto en la planeación ideal de la clase. Entonces, la culpa señala la acción pedagógica como negligente y al docente como el responsable de dicha situación; en palabras de Ramírez (2001), la culpa es la respuesta emocional a regulaciones del self en lo social al comprender la responsabilidad en la falla de un orden moral y ético (p. 188). 


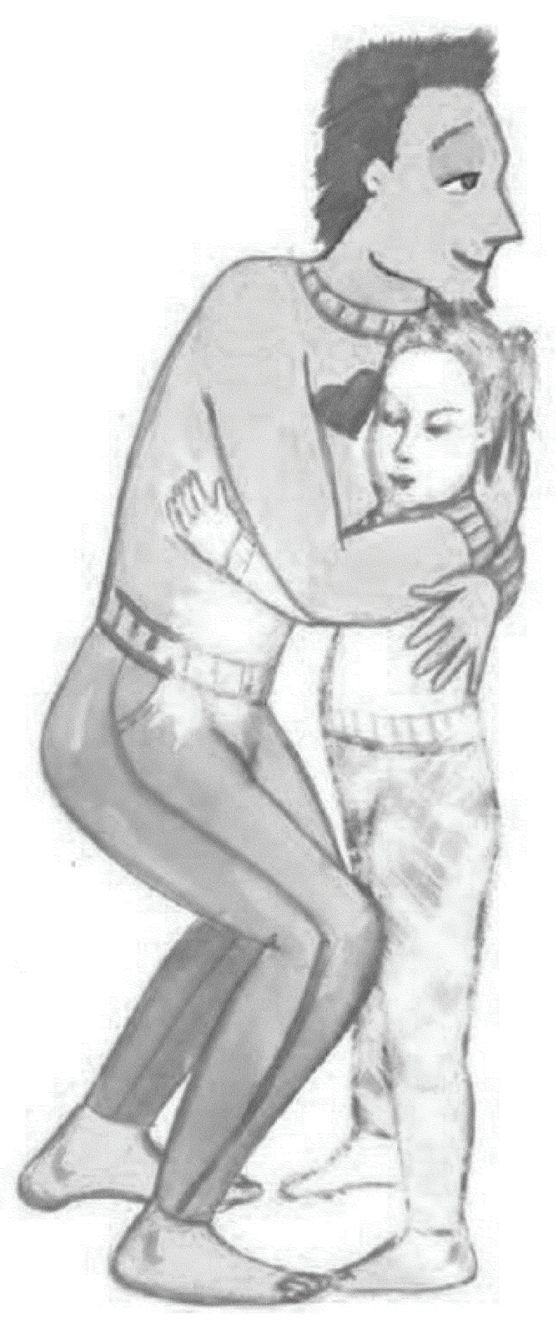

\section{Imagenes, emocionesy \\ sensaciones de los \\ intercambios sensibles en \\ situaciones de riesgo vital \\ Lesionesfisicas del \\ encuentro del cuidado}

Sentimiento de culpa

Sentimiento de compasion

Elcuidado recibido de los estudiantes

\section{encarnacion del cuidar}

Figura 5. Marcas del cuerpo cuidado

Fuente: ilustración elaborada por Diana Otálora.

Durante el día me sentí culpable. Aunque estaba ahí, me preguntaba: ¿Cómo no pude evitar que esto sucediera? Otra vez el riesgo con los zancos.

Como mecanismo de resiliencia, el cuerpo cuidador evalúa las causas y consecuencias del accidente para proveer estrategias de seguridad en las próximas prácticas pedagógicas, y así restituir la confianza en sí mismo y en los estudiantes. De esta manera, el docente es soporte, guía, apoyo, estabilidad, protección y confianza que contribuye en el aprendizaje y el cuidado del estudiante.
El cuidado es lo que permite la revolución de la ternura al dar prioridad a lo social sobre lo individual y al orientar el desarrollo hacia una mejora en la calidad de vida de los seres humanos y de los demás organismos vivos (Boff, 2002, p. 156).

Otro modo de relación del cuerpo cuidador es el autocuidado. En su biografía docente se han registrado experiencias de desgaste y de vulnerabilidad que dejan marcas corporales que requieren sanar. Cuidar de sí es la necesidad de provocar experiencias gratas en la cotidianidad para resignificar su condición corporal y encontrar otros sentidos 
para habitar la escuela. Las marcas que acontecen en estas búsquedas permiten reconfigurar las de desgaste y vulnerabilidad por marcas afectivas, sensibles y creativas que resignifican las dinámicas de concepción, valoración y representación de los modos de habitar el espacio escolar.

Por lo anterior, el cuerpo cuidador está conectado con la escuela, a tal punto que abonarla es abonarse a sí mismo; cuidar de la escuela es cuidarse así mismo. El cuerpo se alimenta de sus propias acciones, se reaviva mediante intercambios sensibles afectivos con su entorno, con acciones que enriquecen su espíritu y su carnalidad. "El cuidado hace que surja un ser humano complejo, sensible, solidario, amable y conectado con todo y con todos en el universo" (Boff, 2002, p. 156). La integridad del docente se fortalece y recupera a través de la palabra, la música, la danza y la imagen, y al mismo tiempo, alimenta y reanima el espíritu de quienes habitan en el territorio escolar.

Por tanto, la encarnación del cuidar, las imágenes de los intercambios sensible en situaciones de riesgo vital, las lesiones físicas del encuentro del cuidado, el sentimiento de compasión y la autoculpa son las marcas del cuerpo cuidador.

El maestro es el jardinero y la escuela el jardín; soy el responsable por la vida de mis plantas que siempre desearé ver florecer de múltiples colores, formas y siluetas, buscando desde cualquier punto el calor de sol.

\section{A MODO DE CIERRE}

El hacer docente no se reduce a una acción meramente intelectual sino que está sujeta a una experiencia corporal de intercambios sensible, emocional, motriz, energético, afectivo, biológico, químico, psicológico, perceptivo..., con el entorno escolar. La escuela, al ser el espacio en donde el docente habita parte de su vida, es uno de los lugares influyentes en la constitución de su corporeidad. Por tanto, el cuerpo es el lugar de la experiencia y el relato desde el cuerpo expresa las dimensiones complejas de su condición corporal.

Desde esta perspectiva, la investigación-creación sobre mi experiencia docente, en una institución educativa distrital, reveló la relación de causalidad entre las marcas en el cuerpo y la experiencia vivida, mediada por concepciones, valoraciones y representaciones incorporadas que influyen en los modos de relación con el entorno escolar. Las marcas en el cuerpo develaron un cuerpo desgastado, un cuerpo vulnerable, un cuerpo autoritario, un cuerpo silenciado, un cuerpo creativo y un cuerpo cuidador de la experiencia del docente en el entorno escolar. Estas experiencias de ser cuerpo docente, interpretadas en los límites de los corporrelatos, evidencian la complejidad de la experiencia humana.

\section{RECONOCIMIENTOS}

Este artículo deviene de una experiencia de investigación y creación que se gestó en la Maestría en Estudios Artísticos de la Facultad de Artes (ASAB) de la Universidad Distrital Francisco José de Caldas, con el apoyo del Centro de Investigaciones y Desarrollo Científico.

\section{REFERENCIAS BIBLIOGRÁFICAS}

Alves V., A. y Nuño P., J. (1996). Problemas de la voz en el profesorado. Interuniversitaria de Formación del Profesorado, 26, 33-42.

Amézquita Q., C. (2012). Características del cuerpo docente público y privado educativo colombiano. Bogotá: Defensoría del Pueblo.

Arón, A.M. y Milicic, N. (2000). Desgaste profesional de los profesores y clima social escolar. Centro de Estudios y Promoción del Buen Trato. Recuperado el 08 de noviembre de 2013, de: http://www.buentrato.cl/pdf/est_inv/desgas/dpa_aron1.pdf

Ayuso M., J.A. (7 de octubre de 2006). Profesión docente y estrés laboral: una aproximación a los conceptos de Estrés Laboral y Burnout. Revista 
Iberoamericana de Educación. Recuperado de: http://www.rieoei.org/deloslectores/1341Ayuso.pdf

Barbero, J.M. (24 de mayo de 2014). Colombia: Ausencia de relato y des-ubicaciones de lo nacional. Mediaciones. Recuperado de: www.mediaciones.net/2001/01/colombia-ausencia-de-relato-y-des-ubicaciones-de-lo- nacional/

Boff, L. (2002). El cuidado esencial. Ética de lo humano, compasión por la tierra. Madrid: Trota.

Cabra, N.A. y Escobar, M.A. (2014). El cuerpo en Colombia. Estado del arte y subjetividad. Bogotá: IDEP.

Cantor, L.C. (2009). Análisis Fono-ergonómico de la disfonía ocupacional en docentes: Influencia del espacio físico en la presencia de disfonía. Tesis de Maestría en Salud y Seguridad en el Trabajo. Bogotá: Universidad Nacional de Colombia.

Cardona R., G. (agosto de 2011). Factores de riesgo psicosocial que afectan el ejercicio pedagógico de los docentes del núcleo educativo $n^{\circ} 8$ de la Ciudadela Cuba de Pereira. Pereira: Universidad Católica de Pereira. Recuperado el 14 de diciembre de 2013, de: http://ribuc.ucp.edu.co:8080/jspui/bitstream/ handle/10785/398/completo.pdf?sequence $=1$

De la Torre R., C. (2007). El malestar docente: un fenómeno de relevancia internacional. La Mancha: Universidad de Castilla. Recuperado el 18 de diciembre de 2013, de: http://stellae.usc.es/red/file/ view/5625/el-malestar-docenteun-fenmeno-de-relevancia-internacional

Decreto 2277 de 1979 (14 de septiembre de 1979). Estatuto Docente. Ministerio de Educación Nacional. Colombia.

Esteban, M.L. (2004). Antropología del cuerpo. Género, itinerarios corporales, identidad y cambio. Barcelona: Ediciones Bellaterra.

Feliu, J. y Lajeunesse, S. (2007). Nuevas formas literarias para las ciencias sociales: el caso de la autoetnografía. Athenea Digital, 12, 262-271.

Figari, C.E. (2009). Las emociones de lo abyecto: repugnancia e indignación. Obtenido de Clacso: Red de Bibliotecas Virtuales de Ciencias Sociales de América Latina y el Caribe. Recuperado de: http://bibliotecavirtual.clacso.org.ar/ar/libros/coedicion/ scribano/
Foucault, M. (2009). Vigilar y castigar. Nacimiento de la prisión. Madrid: Siglo XXI.

Larrosa B., J. (2006). Sobre la experiencia. ALOMA, Revista de Psicología, Ciencias de la Educación y del Deporte Blanquerna, 19, 87-112, Recuperado de: http://www.raco.cat/index.php/Aloma/article/ view/103367/154553

Londoño, R.; Sáenz, J.; Lanziano, C.; Castro, B.; Ariza, V. y Aguirre, M. (2011). Perfiles de los docentes del sector público de Bogotá. Bogotá: IDEP.

Mandoki, K. (2006). Prácticas estéticas e identidades sociales. Prosaica II. México: Siglo XXI.

Myss, C. (2006). Anatomía del espíritu. Barcelona: Ediciones B - Grupo Z.

Pabón, C. (2002). Construcciones de cuerpos. En: M. López C. Expresión y vida: prácticas en la diferencia (pp. 36-79). Bogotá: Grupo de Derechos Humanos - ESAP Publicaciones.

Pedraza, Z. (2011). En cuerpo y alma. Visiones del progreso y la felicidad: Educación, cuerpo y orden social en Colombia (1830-1990). Bogotá: Ediciones Uniandes.

Pérez F., C. y Preciado L., J. (2003). Nódulos de cuerdas vocales. Factores de riesgos en los docentes. Estudio de casos y controles. Acta Otorrinolaringológica Española, 54(4), 253-260.

Preciado, J.; Pérez, C.; Calzada, M. y Preciado, P. (09 de julio de 2015). Frecuencia y factores de riesgo de los trastornos de la voz en el personal docente de La Rioja. Acta Otorrinolaringología Española, 55, 161-170. Recuperado de: http://apps. elsevier.es/watermark/ctl_servlet?_f=10\&pident_articulo=13097050\&pident_usuario=0\&pcontactid=\&pident_revista $=102 \&$ ty $=160 \&$ accion $=$ L\&origen $=$ zonadelectura $\& w e b=w w w . e l s e v i e r$. es\&lan=es\&fichero=102v56n4a13097050pdf001. pdf

Ramírez G., E. (2001). Antropología "compleja" de las emociones humanas. Revista de Filosofía Moral y Política. Isegoría, 25, 177-200. Recuperado de: http://isegoria.revistas.csic.es/index.php/isegoria/ article/viewArticle/589

Rico B., A. (1998). Las fronteras del cuerpo. Crítica de la corporeidad. Quito: Abya-Yala. 
Rodríguez B., D.M. (5 de octubre de 2013). ¿Cuerpos en tensión? Del maestro quemado al maestro vivido. Ponencia presentada en el I Encuentro Nacional de Corporeidad: Giro Corporal. Organizado por la Red Nacional de Estudios sobre el Cuerpo. Bogotá, Colombia.
Tarruella, N.L. y Rodríguez, L.B. (2008). La mirada en la organización corporal del/la docente. Revista Pilquen. Sección Psicopedagogía, 10 [5].

Woods, P. (1998). Investigar el arte de la enseñanza. El uso de la etnografía en la educación. Barcelona: Paidós. 